\title{
Left Ventricular Noncompaction
}

\author{
Fukiko Ichida, MD
}

\begin{abstract}
Left ventricular noncompaction (LVNC) is a recently defined cardiomyopathy characterized by a pattern of prominent trabecular meshwork and deep intertrabecular recesses, and is thought to be caused by arrest of normal endomyocardial morphogenesis. Although LVNC has been classified as a primary cardiomyopathy of genetic origin, its definition and diagnostic criteria are still being debated. Isolated LVNC was thought to be rare; however, heightened awareness has resulted in an increased detection of the morphological features of LVNC in routine clinical practice, especially in the adult population. Clinical manifestations are highly variable, ranging from no symptoms to disabling congestive heart failure, arrhythmias, and systemic thromboemboli. LVNC, like other forms of inherited cardiomyopathy, is genetically heterogeneous and can be inherited as an autosomaldominant or X-linked recessive disorder. It has been linked to mutations in several genes, including LIM domain binding protein 3 (ZASP), $\alpha$-dystrobrevin (DTNA), tafazzin (TAZ/G4.5) and those encoding sarcomeric proteins. However, the relatively small contribution of known mutations to the disease, compared with the higher proportion of familial cases suggests that other elusive genes remain to be identified. (Circ J 2009; 73: 19-26)
\end{abstract}

Key Words: $\alpha$-dystrobrevin; Cardiomyopathy; Myocardial morphogenesis; TAZ; Ventricular noncompaction

$\mathbf{L}$ eft ventricular noncompaction (LVNC) is a relatively new clinicopathologic entity, first described in 1990 , characterized by a pattern of prominent trabecular meshwork and deep intertrabecular recesses communicating with the left ventricular (LV) cavity (Fig 1). This disorder is postulated to be caused by an arrest of the normal process of intrauterine endomyocardial morphogenesis! LVNC has been classified as a primary cardiomyopathy with a genetic origin ${ }^{2}$ and until recently, isolated LVNC was thought to be extremely rare, with a prevalence in adults of $<0.3 \% 3,4$ and an annual incidence in children of $<0.1$ per $100,0005,6$ However, increased awareness and the use of modern ultrasound technology have resulted in increased detection of the morphological features of LVNC in routine clinical practice?-10 In addition, an unexpectedly high percentage of patients fulfilling the current echocardiographic criteria for LVNC has been reported in the adult population!1 The clinical manifestation of LVNC is highly variable, ranging from no symptoms to a progressive deterioration in cardiac function that results in congestive heart failure, arrhythmias, thromboembolic events, and sudden cardiac death, $1,3,7-9$ Up to $40 \%$ of LVNC patients have evidence of familial disease, based on clinical assessment of the family members of probands, and there is significant genetic heterogeneity in this disorder? It has been linked to mutations in several genes, including LIM domain binding protein 3 (ZASP), $\alpha$-dystrobrevin (DTNA), tafazzin (TAZ/G4.5), lamin $\mathrm{A} / \mathrm{C}(L M N A)$, and genes encoding the sarcomeric proteins, $\beta$-myosin heavy chain (MYH7), $\alpha$-cardiac actin (ACTC), and cardiac troponin $\mathrm{T}($ TNNT2)!2-18

In this review, key clinical features, including diagnostic

(Received October 22, 2008; revised manuscript received October 28, 2008; accepted October 30, 2008; released online December 4, 2008) Department of Pediatrics, Faculty of Medicine, Toyama University, Toyama, Japan

Mailing address: Fukiko Ichida, MD, Department of Pediatrics, Faculty of Medicine, Toyama University, 2630 Sugitani, Toyama 9300194, Japan. E-mail: fukiko@med.u-toyama.ac.jp

All rights are reserved to the Japanese Circulation Society. For permissions, please e-mail: cj@j-circ.or.jp criteria, and the emerging concepts of the etiology of LVNC are summarized.

\section{Etiology and Pathogenesis}

LVNC is defined by the presence of prominent trabeculations on the luminal surface of the ventricle, in association with deep recesses that extend into the ventricular wall, but which do not communicate with the coronary circulation! In this regard, LVNC is different from the similar myocardial pattern of "persisting sinusoids" in which the cardiac chamber communicates with the epicardial coronary circulation. "Persisting sinusoids" can frequently be seen in association with congenital heart diseases, such as pulmonary atresia with intact ventricular septum. Prior to the study by Chin et al, Dusek and colleagues described 'spongy myocardium' in 1975; however, most of the hearts they examined had associated congenital malformations, and some of them would now be classified as "persisting sinusoids" rather than noncompaction! ${ }^{19}$ During mid-late embryonic life, the myocardium is the trabecular network of sponge like muscle, when myocardial blood is supplied by diffusion from the intertrabecular spaces that communicate with the heart chambers. Coronary vessels develop during the second embryonic month, after cardiac looping is complete, and after ventricular and atrial septation and valve development have begun. Epicardial coronary growth is associated with the disappearance of "sinusoids" and the transformation of the spongy myocardium into compact musculature ${ }^{19-21}$

The mechanism of LVNC is widely believed to be arrest of myocardial morphogenesis,19 and the morphological similarity between florid examples of noncompaction and the characteristics of the developing heart is striking.1 However, there has been no proof of an arrest in embryonic endomyocardial morphogenesis. Bleyl et al reported the absence of the characteristic features of noncompaction on fetal echocardiography in 3 infants who were subsequently diagnosed with LVNC22 but it is unclear whether their findings were related to limitations of fetal echocardiography 


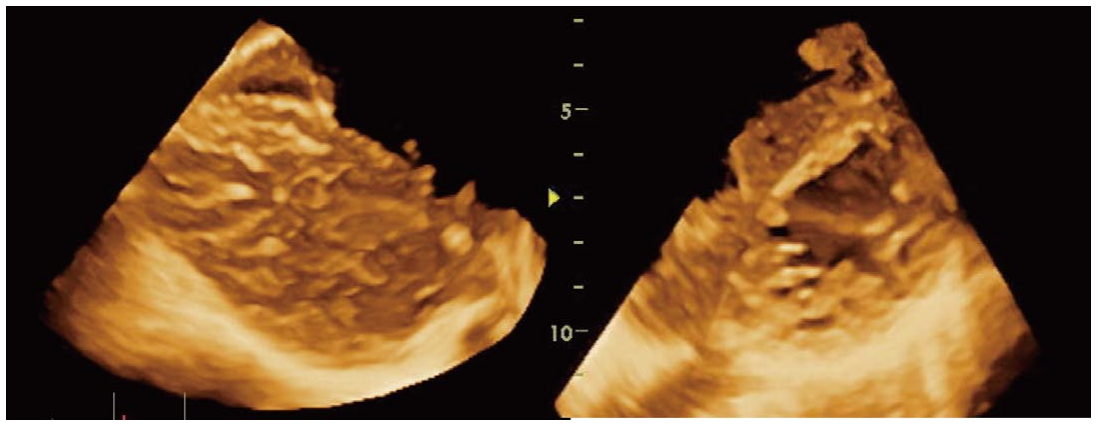

Fig 1. Three-dimensional echocardiogram of a patient with left ventricular noncompaction demonstrating the typical feature of numerous trabeculations and deep intertrabecular recesses at the apex of the left ventricle. (Left) Long-axis view, (Right) short-axis view.

A

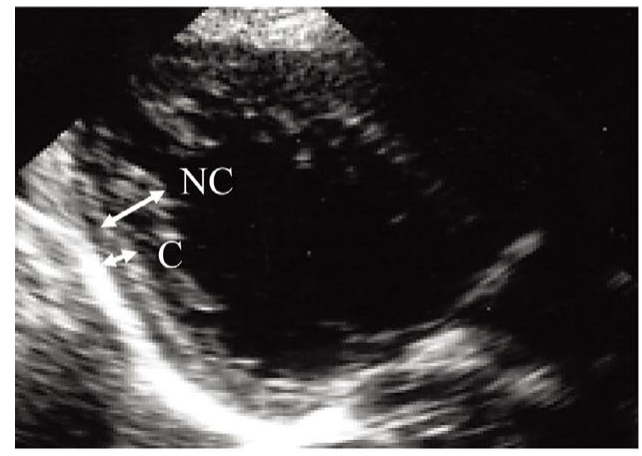

B

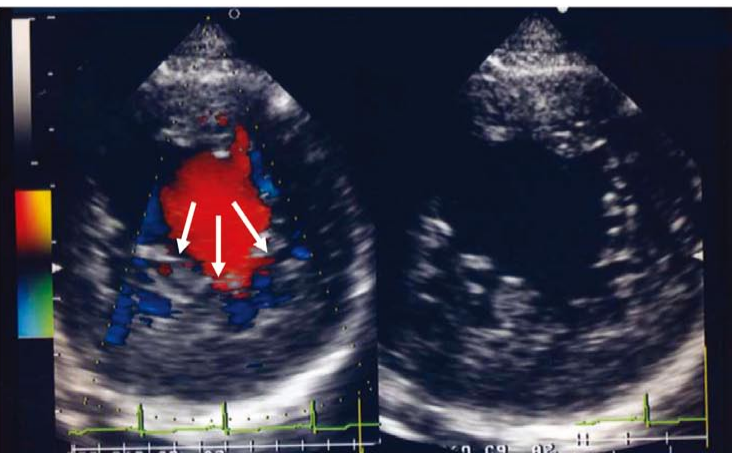

Fig 2. (A) Two-dimensional echocardiogram of a patient with left ventricular noncompaction (LVNC) demonstrating the two-layer structure of non-compacted $(\mathrm{N})$ and compacted $(\mathrm{C})$ layers, N/C $>2.0$. (B) Color Doppler echocardiogram of a patient with LVNC demonstrating flow within the deep intertrabecular recesses (arrow) in continuity with the left ventricular cavity (adapted from Shan et al ${ }^{54}$ with permission).

or to the development of the disorder postnatally. However, there is an increasing number of reports of prenatal diagnosis of LVNC using fetal echocardiography? 23,24 These findings call into question the theory that arrested embryonic development underlies the pathogenesis of LVNC.

In addition, acquired hypertrabeculation/noncompaction, which is indistinguishable from congenital noncompaction, has been reported recently in patients with myotonic dystrophy, ${ }^{25}$ and in the remodeling process of the anatomical right ventricle in corrected transposition of the great arteries ${ }^{26}$ peripartum cardiomyopathy, ${ }^{27}$ and chronic renal failure ${ }^{28}$ especially in adults. Therefore, in some cases of noncompaction in adults it may occur as part of myocardial remodeling after pressure overload or myocardial damage of the ventricle, rather than because of premature arrest of embryonic myocardial morphogenesis.

Two forms of this anomaly have been described, isolated LVNC, which occurs in the absence of other cardiac anomalies, and non-isolated LVNC in which similar myocardial anomaly is frequently reported in association with congenital heart diseases. Associated conditions include coronary artery anomalies (coronary ostial stenosis, anomalous origin of the left main coronary artery from the pulmonary trunk and coronary ventricular fistulae) and conotruncal anomalies (absent pulmonary valve, pulmonary atresia, tricuspid atresia, and transposition of the great arteries), ventricular septal defects, pulmonic stenosis, and atrial septal defects, anomalous venous pulmonary veins, hypoplastic left heart syndrome, Ebstein's anomaly, and histiocytoid cardiomyopathy! 12,29,30 Interestingly, coexistence of LVNC and "Swiss cheese-like" multiple ventricular septal defects may especially explain the maldevelopment of the ventric- ular myocardium as the pathogenesis!2 A recent pathological study revealed that LVNC is frequently associated with other cardiac defects, especially a high incidence of valve anomalies, which often coexist but are not clearly related to the LVNC ${ }^{29}$ The valve anomalies included polyvalvular dysplasia and stenosis, as well as malformed atrioventricular valves, which appeared to be part of the ventricular maldevelopment. In adults, associated cardiac anomalies are rare, presumably because they would result in childhood manifestation.

There is no specific histological finding in LVNC, although fibrosis has been described in many reports?29,31 In 5 individuals with LVNC who underwent right ventricular endomyocardial biopsy, Hamamichi et al described interstitial fibrosis in each, with endomyocardial thickening and subendocardial fibroelastosis in $33^{32} \mathrm{~A}$ histopathological study of 14 cases of LVNC showed that endocardial fibroelastosis was a characteristic histological feature, as well as anastomosing or polypoid endocardial trabeculations, which resulted in staghorn-shaped, endocardial-lined recesses ${ }^{29}$ Right ventricular involvement was seen in 6 of 14 hearts ${ }^{29}$ There were no differences between the cases of isolated and non-isolated LVNC in the histological or gross patterns of the noncompacted regions.

\section{Definition and Diagnostic Criteria}

Although the diagnosis of LVNC is usually made using echocardiography (Figs 1,2), and increasingly magnetic resonance imaging (MRI), which is particularly valuable when good echocardiographic imaging can not be obtained (Fig 3) ${ }^{32-34}$ there is no universally accepted definition of 

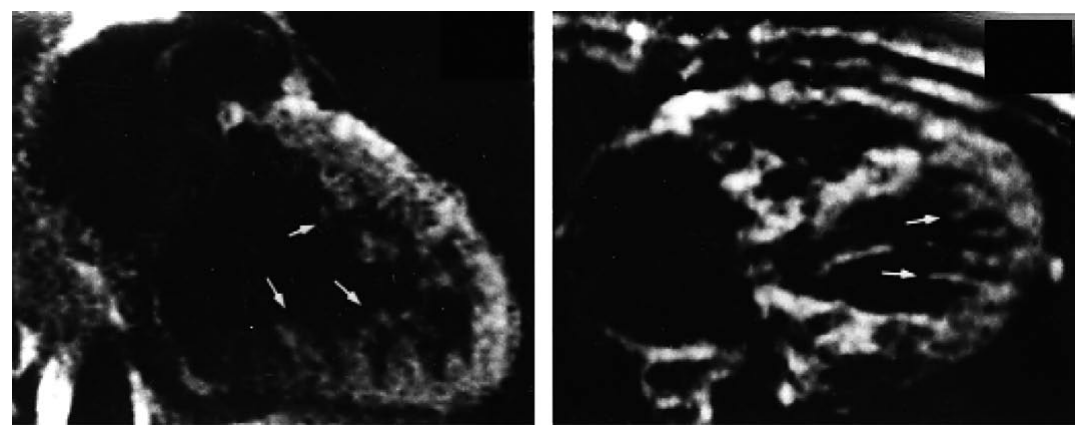

Fig 3. Magnetic resonance imaging of the heart of a patient with left ventricular noncompaction demonstrating prominent, numerous trabeculations (arrows) in the left ventricular apex with deep intertrabecular recesses.

Table 1 Clinical and Demographic Characteristics of Patients With Noncompaction of the Ventricular Myocardium

\begin{tabular}{|c|c|c|c|c|}
\hline & \multicolumn{2}{|c|}{ Children } & \multicolumn{2}{|c|}{ Adults } \\
\hline & Chin $^{1}$ & Ichida ${ }^{8}$ & Ritter $^{3}$ & Oechslin $^{4}$ \\
\hline Patients, number & 8 & 27 & 17 & 34 \\
\hline Males, \% & 63 & 56 & 82 & 74 \\
\hline Median age at diag & 7 & 5 & 45 & 40 \\
\hline Age range, years & $0.9-22.5$ & $0-15$ & $18-71$ & $16-71$ \\
\hline Follow up, years & $\leq 5$ & $\leq 17$ & $\leq 6$ & $\leq 11$ \\
\hline Facial dysmorphism, \% & 38 & 33 & 0 & 0 \\
\hline Familial occurrence, \% & 50 & 44 & 12 & 18 \\
\hline \multicolumn{5}{|c|}{ Localization of noncompacted segments, \% } \\
\hline Apex & Most prominent & 100 & 100 & 94 \\
\hline Inferior wall & - & 70 & 100 & 94 \\
\hline Lateral wall & - & 41 & - & 100 \\
\hline Abnormal ECG, \% & 88 & 88 & 88 & 94 \\
\hline Bundle branch block & 25 & 15 & 47 & 56 \\
\hline WPW syndrome & 13 & 15 & 0 & 0 \\
\hline Ventricular tachycardia & 38 & 0 & 47 & 41 \\
\hline Atrial fibrillation & - & - & 29 & 26 \\
\hline LV systolic dysfunction, $\%$ & 63 & 60 & 76 & 82 \\
\hline Congestive heart failure, \% & 63 & 30 & 53 & 68 \\
\hline \multicolumn{5}{|l|}{ Thromboembolism, \% } \\
\hline Systemic embolism & 38 & 0 & 24 & 21 \\
\hline Pulmonary embolism & 0 & 7 & 6 & 9 \\
\hline Ventricular thrombi & 25 & 0 & 6 & 9 \\
\hline Heart transplantation, $\%$ & 0 & 4 & 12 & 12 \\
\hline Deceased, \% & 38 & 7 & 47 & 35 \\
\hline Sudden death & 13 & 0 & 18 & 18 \\
\hline
\end{tabular}

WPW, Wolff-Parkinson-White; $L V$, left ventricle.

Adapted and modified from Rigopoulos et al ${ }^{37}$ with permission.

LVNC. Current echocardiographic criteria for diagnosis typically include the following: ${ }^{1,9,11,34}$

- presence of prominent or numerous LV trabeculations, predominantly in the distal portion (apex) of the LV (Fig 1)

- two-layered appearance of the myocardium, with an increased noncompacted to compacted ratio (suggested as $>1.4$ in children and as $>2.0$ in adults) (Fig 2A)

- multiple deep intertrabecular recesses communicating with the ventricular cavity, as demonstrated by color Doppler imaging (Fig 2B).

A recent echocardiographic study of 199 patients (age $63.5+15.9$ years) with LV systolic impairment showed that 47 patients $(23.6 \%)$ fulfilled 1 or more of the echocardiographic definitions for LVNC!1 $\mathrm{LVNC}$ was more common in black individuals. In addition, 5 controls (of whom 4 were black) fulfilled 1 or more LVNC criteria. That study demonstrated an unexpectedly high percentage of patients with heart failure fulfilling the current echocardiographic criteria for LVNC, which might be explained by a hitherto underestimated cause of heart failure, but comparison with the controls suggests that the current diagnostic criteria result in over-diagnosis of LVNC in patients with LV systolic dysfunction. In order to avoid unnecessary investigations and treatment, large and detailed studies of normal individuals of different racial origin are required to determine the upper limits of normal trabecular patterns.

Abnormalities of the resting ECG are found in the majority of patients with LVNC, but the findings are nonspecific and include LV hypertrophy, repolarization changes, inverted $\mathrm{T}$ waves, ST segment changes, axis shifts, intraventricular conduction abnormalities, and AV block. Typical patients with isolated LVNC have an ECG demonstrating biventricular hypertrophy with extreme QRS voltages, similar to those seen in infants with Pompe's disease, and isolated or diffuse T-wave changes. A high incidence of Wolff-Parkinson-White (WPW) has been reported in children, $8,35,36$ to which arrest of the normal process of development in the annulus fibrosus can be attributed 35

\section{Clinical Presentation}

The triad of heart failure symptoms, arrhythmias and embolic events is the major clinical manifestation in 
Table 2 Gene Mutations Reported in Human LVNC

\begin{tabular}{|c|c|c|c|c|}
\hline Gene & Disease & Location & References & Child/adult \\
\hline$\alpha$-Dystrobrevin (DTNA) & $\begin{array}{l}\text { LVNC with CHD, muscular } \\
\text { dystrophy in human }\end{array}$ & $18 q 12$ & 12 & Child \\
\hline G4.5 (TAZ) & $\begin{array}{l}\text { Barth syndrome, } \\
\text { LVNC, DCM, EFE }\end{array}$ & $X q 28$ & $12,14,15$ & Child \\
\hline LIM domain binding protein (LDB3, Cypher/ZASP) & $\angle V N C, D C M$ & $10 q 22-q 23.2$ & 13,16 & Child/adult \\
\hline $\operatorname{Lamin} A / C$ & $\begin{array}{l}\text { LVNC, DCM, muscular } \\
\text { dystrophy in human }\end{array}$ & $1 q 22$ & 17 & Child/adult \\
\hline \multicolumn{5}{|l|}{ Sarcomere proteins } \\
\hline$\beta$-myosin heavy chain (MYH7) & $H C M, D C M, L V N C$ & $14 q 11.2-q 13$ & 18 & Adult \\
\hline$\alpha$-cardiac actin $(A C T C)$ & $H C M, D C M, L V N C$ & $15 q 11-q 14$ & 18 & Adult \\
\hline Cardiac troponin $T$ (TNNT2) & $H C M, D C M, L V N C$ & $1 q 32$ & 18 & Adult \\
\hline
\end{tabular}

LVNC, left ventricular noncompaction; CHD, congenital heart disease; DCM, dilated cardiomyopathy; EFE, endocardial fibroelastosis; HCM, hypertrophic cardiomyopathy.

patients with reduced systolic LV function and is comparable in the adult and pediatric populations!,3,4,7-9,37 Various patterns of arrhythmia, ranging from atrial fibrillation to sustained ventricular tachycardia, can be observed. Clinical presentation is quite variable among patients, ranging from asymptomatic to severe disabling congestive heart failure, even in the same family ${ }^{38}$ The natural history of LVNC is largely unsolved, but includes progressive heart failure (requiring transplantation in some cases), thromboembolic events, arrhythmias, sudden death, and diverse forms of remodeling. An "undulating" phenotype characterized by periods of recovery and deterioration, with survival into adulthood was described in the largest pediatric series to date comprising 36 children? In a population of Japanese children with LVNC followed for up to 17 years, LV dysfunction developed in the vast majority, regardless of the presence or absence of symptoms at initial diagnosis? In Japan, LVNC is detected during school screening examinations of asymptomatic children, and might have a longer clinical course with gradually depressed LV function.

Comparing the clinical presentations of children and adults in previous studies (Table 1), 1,3,4,8 the most striking differences are the lack of facial dysmorphism and of WPW syndrome in the adult population, which may be related to a difference in the underlying etiology. Furthermore, a lower familial occurrence in the adult population may be explained by incomplete screening of the siblings. Secondary arrhythmias, such as atrial fibrillation, are more common in adults with IVNC. Other important clinical features, such as symptoms of heart failure, ventricular tachycardias, systemic embolic events, pulmonary embolism or the location of noncompacted segments, are comparable between the adult and pediatric populations.

Depressed LV systolic dysfunction is the most common finding in both the pediatric and adult population (up to two-thirds of the patients), and usually depend on the extent of noncompacted cardiac segments. Both systolic and diastolic ventricular dysfunction has been described. Tissue Doppler-derived indices of LV diastolic relaxation are significantly reduced in patients with LVNC, and predict children who are at risk of adverse clinical outcome, including death or the need for cardiac transplantation 39,40 Restrictive hemodynamics identified by cardiac catheterization, as well as an initial presentation of LVNC as a restrictive cardiomyopathy in children with LVNC, have been described? Diastolic dysfunction in ventricular noncompaction may be related to both abnormal relaxation and restrictive filling caused by the numerous prominent trabeculae.
The origin of systolic dysfunction in noncompaction is unclear, with subendocardial hypoperfusion and microcirculatory dysfunction playing a role in the ventricular dysfunction and arrhythmogenesis. Subendocardial perfusion defects have been described in LVNC, using cardiac MRI?2,33,41 Positron emission tomography ${ }^{32,42,43}$ and scintigraphy with thallium- $201^{32}$ have demonstrated transmural perfusion defects that correlate with areas of noncompacted myocardium in LVNC. Impaired microvascular function may account for the contractile dysfunction. ${ }^{43}$

In patients with LVNC, mechanical dyssynchrony is obvious between noncompacted and compacted myocardium, and contribute to global LV dysfunction ${ }^{44,45}$ Successful cardiac resynchronization therapy in patients with isolated LVNC has been reported recently, both in a child and adults 44,45

\section{Genetic Considerations}

Up to $44 \%$ of patients in clinical series have a family history of cardiomyopathy; $;^{1,3,4,8}$ in children, X-linked, autosomal dominant and mitochondrial inheritance have been reported, while in adults autosomal dominant inheritance has been described 46 The likely mode of inheritance in 44 familial cases ( 20 families) has been characterized: autosomal dominant inheritance was the most common whereas X-linked inheritance was apparent in only 5 families! ${ }^{16}$ In addition, the clinical manifestations in all the patients varied greatly, even between family members carrying the same mutation, as seen in other forms of inherited cardiomyopathies! ${ }^{16}$

Etiologic studies of LVNC are increasing rapidly (Table 2). There have been reports of mutations in several genes, including taffazin (TAZ/G4.5), LIM domain binding protein 3 (ZASP/LDB3), $\alpha$-dystrobrevin (DTNA), and lamin $\mathrm{A} / \mathrm{C}(L M N A)$ (Table 2)!2-17 However, genetic studies have been limited, and specific gene defects are infrequently identified, suggesting genetic heterogeneity!2,14,16 Therefore, the genetic basis of disease in a large proportion of patients with LVNC is still unresolved.

My group investigated 103 Japanese LVNC patients, including 44 cases from 20 families and 59 sporadic cases, for disease-causing mutations in a series of selected candidate genes 16 Of these, 88 were isolated cases and 15 were non-isolated cases. DNA variants were identified in 17 patients, including 15 cases from 4 families and 2 sporadic cases. A TAZ mutation was identified in 1 family and 1 sporadic case, a DTNA variant in a non-isolated family and 


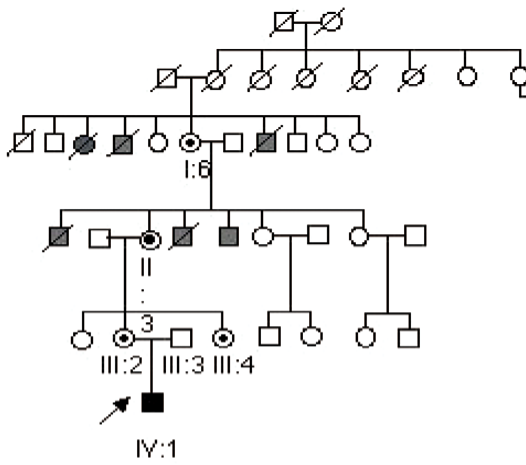

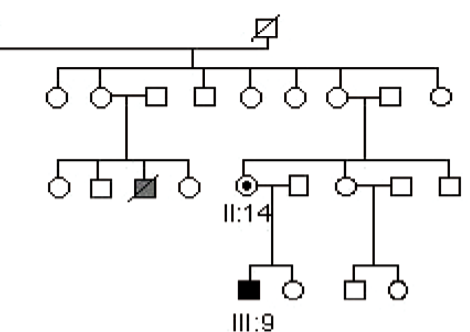

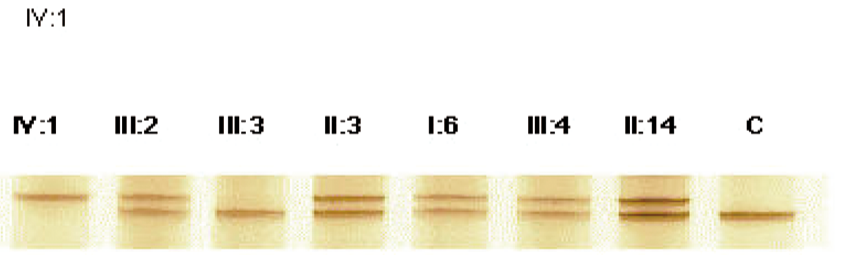

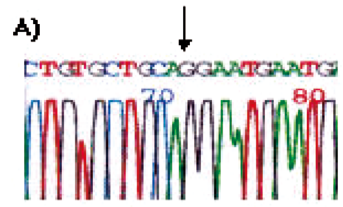

B)

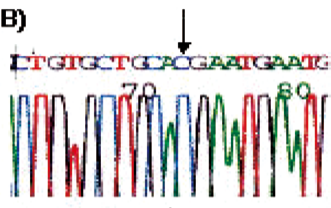

C) CTCIGCTGCACGAXTCAATE

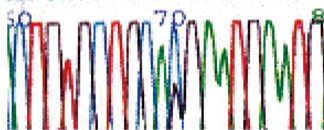

\section{A family with isolated LVNC $\mathrm{TAZ}$, Intron 8, G $\rightarrow \mathrm{C}$, Splice-site mutation}

\section{deletion of exon 9}

Fig 4. (Left upper panel) Pedigree of an extended family with isolated left ventricular noncompaction (LVNC). Squares indicate males; circles represent females; solid-filled squares represent affected males; circles with dots represent carrier females; and slashes indicate dead individuals. The pedigree reveals a history of unexplained death during infancy and early childhood, indicated by hatched symbols. The presentation is compatible with an X-linked recessive inheritance. The proband (patient IV:1) is indicated by an arrow. (Left lower panel) SSCP analysis of exon 9 of $T A Z$ in the proband (IV:1), his mother (III:2), father (III:3), grandmother (II:3), great grandmother (I:6), aunt (III:4), as well as the mother (II:14) of the second patient (III:9), and a normal unrelated control (C). (Right panel) DNA sequence analysis of intron 8 and exon 9 of TAZ in a normal control (Panel A), the proband (Panel B) and his mother, a heterozygous carrier (III:2) (Panel C). IVS8-1G>C substitution is identified (adapted from Chen et al ${ }^{15}$ with permission).

2 variants in $L D B 3$.

\section{$T A Z(G 4.5)$}

A splice acceptor mutation in intron 8 of TAZ (IVS8$1 \mathrm{G}>\mathrm{C}$ ) was identified in 1 family with isolated LVNC, resulting in deletion of exon 9 from the mRNA. 15 This large family, with apparent $\mathrm{X}$-linked recessive inheritance of LVNC over 4 generations (Fig 4), has a second affected individual (patient III:9). Analysis of the pedigree further revealed a history of unexplained male infant death. The proband presented with signs of heart failure and was admitted to hospital at 3 months of age. Two-dimensional echocardiography and LV angiography revealed a hypertrophic and dilated left ventricle with severely noncompacted myocardium and reduced systolic function. The second affected individual presented with signs and symptoms of congestive heart failure at 2 months of age, and 2dimensional echocardiography showed typical findings of isolated LVNC with reduced systolic function. Neither of the affected individuals nor any other family members presented with signs or symptoms of Barth syndrome. Female carriers did not show any abnormal findings indicative of LVNC or reduced systolic function on echocardiography. In a sporadic case of isolated LVNC and Barth syndrome, a 158insC mutation was identified in exon 2 of $T A Z$, resulting in a frame-shift. 15,16

TAZ (G4.5) is located on Xq28 and was initially identified in patients with Barth syndrome, a complex X-linked disorder that presents in infant males and is classically characterized by dilated cardiomyopathy, neutropenia,

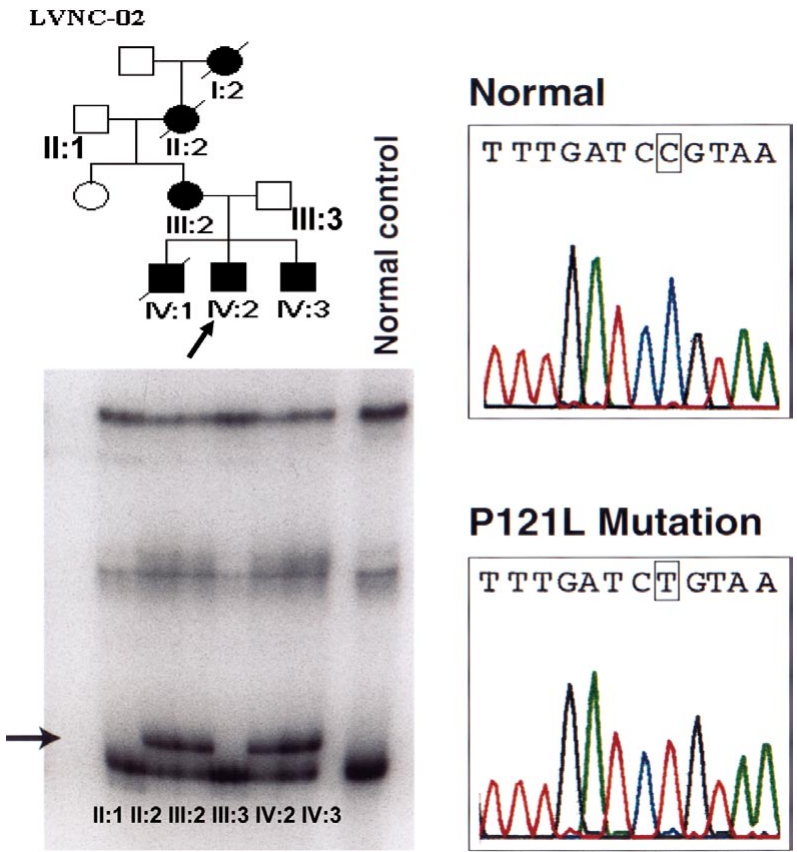

Fig 5. (Left upper panel) Pedigree of a 4-generation family with 6 affected patients. Detection of mutations in DTNA. (Left lower panel) SSCP analysis identifies an abnormal band (arrow) in affected members of this family. (Right panel) Automated sequencing of the abnormal band identifies a point mutation $(362 \mathrm{C}>\mathrm{T})$ within exon 3 of DTNA in the affected individuals, resulting in a Pro121Leu substitution (adapted from Ichida et $\mathrm{al}^{8}$ with permission). 
LVNC-04

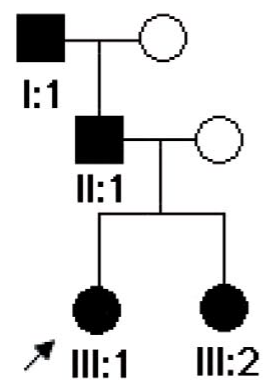

LVNC-18

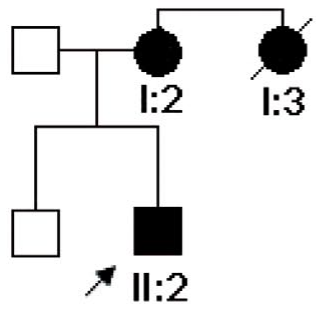

(A)

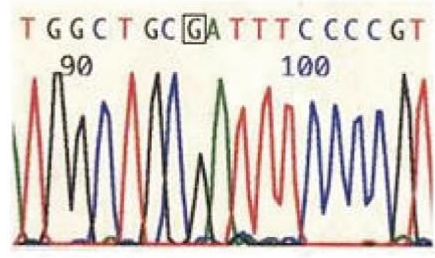

(B)

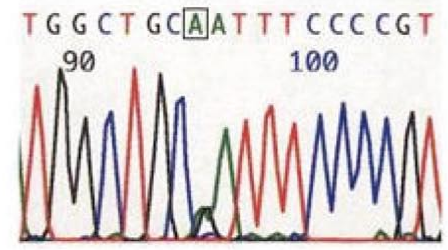

(C)

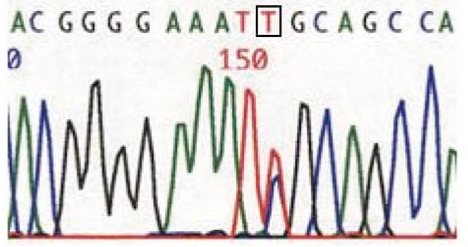

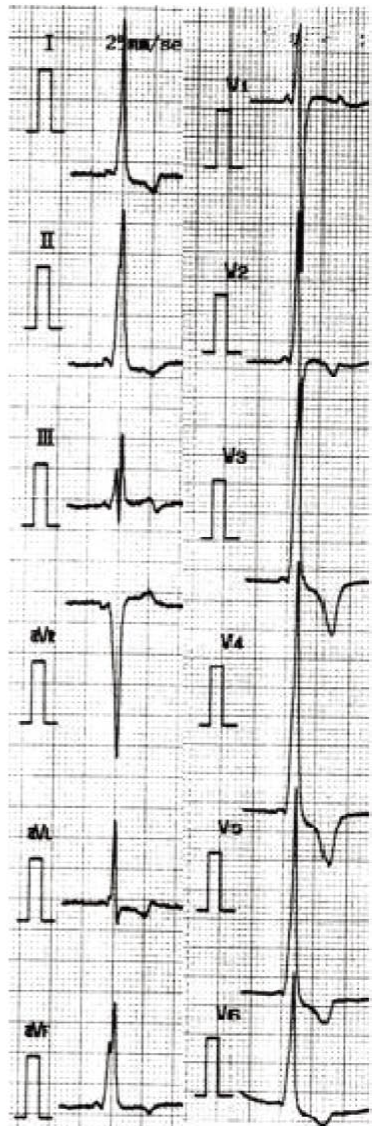

Fig 6. (Left panel) Pedigrees of 2 families with $L D B 3$ variants. (Middle panel) DNA sequence analysis of exon 15 of LDB3 in a normal control (Panel A), and in the proband of LVNC-04 (III:1), showing the 1876G > A variant detected in both the forward (Panel B) and reverse (Panel C) sequences, resulting in the Asp626Asn substitution (Right panel) ECG of the proband who presented WPW syndrome from LVNC-18 (adapted from Xing et al ${ }^{16}$ with permission).

abnormal cholesterol metabolism, lactic acidosis, and elevated levels of 3-methylglutaconic acid and 2-ethylhydracrylic acid, and cardiolipin abnormalities.47,48 Some patients have been found to have LVNC as well47,48 The products of this gene, known as tafazzins, are expressed primarily in heart and muscle cells, and are proposed to have acyltransferase functions within mitochondria. ${ }^{4}$ TAZ mutations have been identified repeatedly in some of the larger series of LVNC, but account for a small proportion of cases. ${ }^{12,14-16}$

\section{DTNA}

A family with non-isolated LVNC had a $362 \mathrm{C}>\mathrm{T}$ substitution in exon 3 of DTNA, resulting in an amino acid change from proline to leucine at codon 121 (P121L)!2,16 This is a 4-generation family with 6 affected patients, including 5 with non-isolated LVNC and 1 with isolated LVNC (Fig 5). The age range at the time of diagnosis was 2 days to 69 years old. There is considerable variability in disease development and severity in this family. One child died with a hypoplastic left heart and hydrops fetalis diagnosed after birth, and another 2 children were identified with patent ductus arteriosus and "Swiss cheese-like" multiple ventricular septal defect. $\alpha$-Dystrobrevin is a member of the dystrophin-associated glycoprotein complex (DAPC), and binds dystrophin, syntrophin and other proteins of DAPC, which is thought to play an important role in the stability and maintenance of the plasma membrane during muscle contraction and relaxation. Furthermore, $\alpha$-dystrobrevin links DAPC to the signaling protein, neuronal nitric oxide synthase (nNOS) $)^{50}$

Disruption of these links results in severe muscle wasting or cardiac muscle pathology. Absence of $\alpha$-dystrobrevin has been shown to result in muscular dystrophy in humans ${ }^{51}$ and has also been found to cause skeletal myopathy and cardiomyopathy in mice 52 Of particular interest is the description by Grady et al of a mouse deficient in $\alpha$-dystrobrevin, derived by homozygous deletion of exon 3 , whereby reduced signaling via nNOS results in skeletal and cardiac (degenerating myocytes, mononuclear cell infiltration, and fibrosis) myopathies $5^{2}$ These data suggest that the region of the gene encoded by exon 3 , the same region as mutated in the patient described here, is essential for functionality of the protein.

\section{$L D B 3$}

The $1876 \mathrm{G}>\mathrm{A}$ substitution changing an aspartic acid to asparagine (D626N) was identified in LDB3 in 4 members of 2 families with LVNC (Fig 6) 16 The proband (II:2) of a 2-generation family was initially diagnosed with isolated LVNC and WPW syndrome in a school screening examination when he was 13 years old. On echocardiography, multiple prominent ventricular trabeculations with deep intertrabecular recesses were seen in the apical wall and the mid-ventricular segments of both the lateral and posterior walls of the LV. Additionally, evaluation of family 
members revealed that his maternal aunt (I:3) had died suddenly with indistinct cardiac disease at the age of 10 . The same LDB3 D626N substitution was identified in another affected child and his mother (I:2), who was also diagnosed with LVNC on echocardiography, but who had no clinical symptoms. $L D B 3$, also known as ZASP, the Z-band alternatively spliced PDZ-motif protein, or Cypher, is a PDZ and LIM domain-containing cytoskeletal protein that has been shown to result in cardiomyopathy when knocked out in mice $5^{5}$ Other groups have reported the presence of variants in $L D B 3$ in patients with LVNC as well! 3

In our study, the incidence of mutations in the genes encoding TAZ/G4.5, DTNA and $L D B 3$ was only $17 \% ! 6$ The relatively small contribution of known mutations to the disease, compared with the higher proportion of familial cases, suggests that other elusive genes remain to be identified. A recent study identified variants in sarcomeric protein-encoding genes, including $\beta$-myosin heavy chain (MYH7), $\alpha$-cardiac actin (ACTC), and cardiac troponin $\mathrm{T}$ (TNNT2), in adults with LVNC! ${ }^{18}$ Variants in these genes have previously been associated with hypertrophic and dilated cardiomyopathy 18 Their findings support the concept that LVNC is part of a diverse spectrum of cardiac morphologies triggered by sarcomere protein gene defects and that there is a shared molecular etiology of different cardiomyopathic phenotypes.

In addition, the prevalence of $S C N 5 A$ variants is significantly higher in LVNC patients with arrhythmias and/or heart failure than in those without, supporting the hypothesis that genes encoding ion channels are implicated in the pathophysiology of LVNC, modifing the severity of disease ${ }^{54}$

Chromosomal anomalies and syndromes are also associated with noncompaction of the ventricles, including Barth syndrome ${ }^{12}$ which may be genetically related, congenital adrenal hyperplasia, DiGeorge syndrome? myopathic changes with inclusions in skeletal muscle fibers? and Melnick-Needles syndrome,5 Roifman's syndrome,56 Charcot-Marie-Tooth disease ${ }^{57}$ and metabolic disorders such as Fabry's disease 58 and chromosomal anomalies of 13 trisomy 59 chromosome $5 \mathrm{q}$ deletion ${ }^{60}$ and $1 \mathrm{q} 43$ deletion61 Mitochondrial diseases, such as mitochondrial enzyme complex II deficiency, may be another cause of LVNC and potentially lethal ${ }^{6}$

\section{Conclusion}

The clinical presentation of LVNC is highly variable, ranging from asymptomatic to severe heart failure and sudden death, which often causes delayed diagnosis of this newly recognized cardiomyopathy. Higher occurrence of familial cases, facial dysmorphism and congenital arrhythmias, such as WPW syndrome, are noted in children, whereas secondary arrhythmias, such as atrial fibrillation, are more common in adults. The mode of inheritance is predominantly autosomal dominant, and sarcomere protein mutations are more common in adults. These different findings suggest a different underlying etiology between children and adult cases of this clinical entity. The high incidence of LVNC in adults suggests that the hypertrabeculation occurs secondary to other events and that LVNC may be currently over-diagnosed because of the sensitive diagnostic criteria, which should be reappraised.

\section{Acknowledgments}

Fukiko Ichida is supported by grants from the Ministry of Education, Culture, Sports, Science and Technology in Japan (Grant-in-Aid for Scientific Research Nos. 10670708, 12670734, 15591094, 17591072, 20591274), from Novartis Foundation (Japan) for the Promotion of Science (2005), and from Miyata Cardiac Research Promotion Foundation (2003).

\section{References}

1. Chin TK, Perloff JK, Williams RG, Jue K, Mohrmann R. Isolated noncompaction of left ventricular myocardium: A study of eight cases. Circulation 1990; 82: 507-513.

2. Maron BJ, Towbin JA, Thiene G, Antzelevitch C, Corrado D, Arnett D, et al; American Heart Association; Council on Clinical Cardiology, Heart Failure and Transplantation Committee; Quality of Care and Outcomes Research and Functional Genomics and Translational Biology Interdisciplinary Working Groups; Council on Epidemiology and Prevention. Contemporary definitions and classification of the cardiomyopathies: An American Heart Association Scientific Statement from the Council on Clinical Cardiology, Heart Failure and Transplantation Committee; Quality of Care and Outcomes Research and Functional Genomics and Translational Biology Interdisciplinary Working Groups; and Council on Epidemiology and Prevention. Circulation 2006; 113: 1807-1816.

3. Ritter M, Oechslin E, Sutsch G, Attenhofer C, Schneider J, Jenni R. Isolated noncompaction of the myocardium in adults. Mayo Clin Proc 1997; 72: 26-31.

4. Oechslin EN, Attenhofer Jost CH, Rojas JR, Kaufmann PA, Jenni R. Long-term follow-up of 34 adults with isolated left ventricular noncompaction: A distinct cardiomyopathy with poor prognosis. $\mathrm{J} \mathrm{Am}$ Coll Cardiol 2000; 36: 493-500.

5. Nugent AW, Daubeney PE, Chondros P, Carlin JB, Cheung M, Wilkinson LC, et al. National Australian Childhood Cardiomyopathy Study: The epidemiology of childhood cardiomyopathy in Australia. N Engl J Med 2003; 348: 1639-1646.

6. Lipshultz SE, Sleeper LA, Towbin JA, Lowe AM, Orav EJ, Cox GF, et al. The incidence of pediatric cardiomyopathy in two regions of the United States. N Engl J Med 2003; 348: 1647-1655.

7. Pignatelli RH, McMahon CJ, Dreyer WJ, Denfield SW, Price J, Belmont JW, et al. Clinical characterization of left ventricular noncompaction in children: A relatively common form of cardiomyopathy. Circulation 2003; 108: 2672-2678.

8. Ichida F, Hamamichi Y, Miyawaki T, Ono Y, Kamiya T, Akagi T, et al. Clinical features of isolated noncompaction of the ventricular myocardium: Long-term clinical course, hemodynamic properties, and genetic background. J Am Coll Cardiol 1999; 34: 233-240.

9. Jenni R, Oechslin EN, van der Loo B. Isolated ventricular noncompaction of the myocardium in adults. Heart 2007; 93: 11-15.

10. Stollberger C, Finsterer J, Blazek G. Left ventricular hypertrabeculation, noncompaction and association with additional cardiac abnormalities and neuromuscular disorders. Am J Cardiol 2002; 90: 899-902.

11. Kohli SK, Pantazis AA, Shah JS, Adeyemi B, Jackson G, McKenna WJ, et al. Diagnosis of left-ventricular non-compaction in patients with left-ventricular systolic dysfunction: Time for a reappraisal of diagnostic criteria? Eur Heart J 2008; 29: 89-95.

12. Ichida F, Tsubata S, Bowles KR, Haneda N, Uese K, Miyawaki T, et al. Novel gene mutations in patients with left ventricular noncompaction or Barth syndrome. Circulation 2001; 103: 1256-1263.

13. Vatta M, Mohapatra B, Jimenez S, Sanchez X, Faulkner G, Perles Z, et al. Mutations in Cypher/ZASP in patients with dilated cardiomyopathy and left ventricular non-compaction. J Am Coll Cardiol 2003; 42: $2014-2027$.

14. Kenton AB, Sanchez X, Coveler KJ, Makar KA, Jimenez S, Ichida $\mathrm{F}$, et al. Isolated left ventricular noncompaction is rarely caused by mutations in G4.5, alpha-dystrobrevin and FK Binding Protein-12. Mol Genet Metab 2004; 82: 162-166.

15. Chen R, Tsuji T, Ichida F, Bowles KR, Yu X, Watanabe S, et al. Mutation analysis of the G4.5 gene in patients with isolated left ventricular noncompaction. Mol Genet Metab 2002; 77: 319-325.

16. Xing $Y$, Ichida F, Matsuoka $T$, Isobe $T$, Ikemoto $Y$, Higaki $T$, et al. Genetic analysis in patients with left ventricular noncompaction and evidence for genetic heterogeneity. Mol Genet Metab 2006; 88: 71 77.

17. Hermida-Prieto M, Monserrat L, Castro-Beiras A, Laredo R, Soler R, Peteiro J, et al. Familial dilated cardiomyopathy and isolated left venricular noncompaction associated with lamin $\mathrm{A} / \mathrm{C}$ gene mutations. Am J Cardiol 2004; 94: 50-54.

18. Klaassen S, Probst S, Oechslin E, Gerull B, Krings G, Schuler P, et al. Mutations in sarcomere protein genes in left ventricular noncom- 
paction. Circulation 2008; 117: 2893-2901.

19. Dusek J, Ostadal B, Duskova M. Postnatal persistence of spongy myocardium with embryonic blood supply. Arch Pathol 1975; 99: $312-317$.

20. Jenni R, Goebel N, Tartini R, Schneider J, Arbenz U, Oelz O. Persisting myocardial sinusoids of both ventricles as an isolated anomaly: Echocardiographic, angiographic, and pathologic anatomical findings. Cardiovasc Intervent Radiol 1986; 9: 127-131.

21. Freedom RM, Yoo SJ, Perrin D, Taylor G, Petersen S, Anderson RH. The morphological spectrum of ventricular noncompaction. Cardiol Young 2005; 15: 345-364.

22. Bleyl SB, Mumford BR, Brown-Harrison MC, Pagotto LT, Carey JC, Pysher TJ, et al. Xq28-linked noncompaction of the ventricular myocardium: Prenatal diagnosis and pathologic analysis of affected individuals. Am J Med Genet 1997; 72: 257-265.

23. Brady AN, Shehata BM, Fernhoff PM. X-linked fetal cardiomyopathy caused by a novel mutation in the TAZ gene. Prenat Diagn 2006; 26: $462-465$.

24. Menon SC, O'Leary PW, Wright GB, Rios R, MacLellan-Tobert SG, Cabalka AK. Fetal and neonatal presentation of noncompacted ventricular myocardium: Expanding the clinical spectrum. J Am Soc Echocardiogr 2007; 20: 1344-1350.

25. Hofer M, Stollberger C, Finsterer J. Acquired noncompaction associated with myopathy. Int J Cardiol 2007; 121: 296-297.

26. Kawakubo M, Funabashi N, Uehara M, Ueda M, Hasegawa $H$, Sekine T, et al. Appearance of noncompaction-like remodeling of the anatomical right ventricle in a middle-aged subject with modified transposition of the great arteries who did not undergo surgery. Int $J$ Cardiol 2007; 122: 161-163.

27. Rehfeldt KH, Pulido JN, Mauermann WJ, Click RL. Left ventricular hypertrabeculation/noncompaction in a patient with peripartum cardiomyopathy. Int J Cardiol 2008; Sep 13 [Epub ahead of print].

28. Markovic NS, Dimkovic N, Damjanovic T, Loncar G, Dimkovic S. Isolated ventricular noncompaction in patients with chronic renal failure. Clin Nephrol 2008; 70: 72-76.

29. Burke A, Mont E, Kutys R, Virmani R. Left ventricular noncompaction: A pathological study of 14 cases. Hum Pathol 2005; 36: $403-$ 411.

30. Attenhofer Jost CH, Connolly HM, Warnes CA, O'leary P, Tajik AJ, Pellikka PA, et al. Noncompacted myocardium in Ebstein's anomaly: Initial description in three patients. $J$ Am Soc Echocardiogr 2004; 17: $677-680$

31. Finsterer J, Stollberger C, Feichtinger H. Histological appearance of left ventricular hypertrabeculation/noncompaction. Cardiology 2002; 98: $162-164$

32. Hamamichi Y, Ichida F, Hashimoto I, Uese KH, Miyawaki T, Tsukano $\mathrm{S}$, et al. Isolated noncompaction of the ventricular myocardium: Ultrafast computer tomography and magnetic resonance imaging. Int J Cardiovasc Imaging 2001; 17: 305-314.

33. Daimon Y, Watanabe S, Takeda S, Hijikata Y, Komuro I. Twolayered appearance of noncompaction of the ventricular myocardium on magnetic resonance imaging. Circ J 2002; 66: 619-621.

34. Jenni R, Oechslin E, Schneider J, Attenhofer Jost C, Kaufmann PA Echocardiographic and pathoanatomical characteristics of isolated left ventricular non-compaction: A step towards classification as a distinct cardiomyopathy. Heart 2001; 86: 666-671.

35. Nihei K, Shinomiya N, Kabayama H, Ikeda C, Hosono T, Aoki T, et al. Wolff-Parkinson-White (WPW) syndrome in isolated noncompaction of the ventricular myocardium (INVM). Circ J 2004; 68: 82-84.

36. Yasukawa K, Terai M, Honda A, Kohno Y. Isolated noncompaction of ventricular myocardium associated with fatal ventricular fibrillation. Pediatr Cardiol 2001; 22: 512-514.

37. Rigopoulos A, Rizos IK, Aggeli C, Kloufetos P, Papacharalampous $\mathrm{X}$, Stefanadis C, et al. Isolated left ventricular noncompaction: An unclassified cardiomyopathy with severe prognosis in adults. Cardiology 2002; 98: $25-32$.

38. Johnson MT, Zhang S, Gilkeson R, Amador R, Siwik E, Patel CR, et al. Intrafamilial variability of noncompation of the ventricular myocardium. Am Heart J 2006; 151: 1012.e7-1012.e14.

39. McMahon CJ, Pignatelli RH, Nagueh SF, Lee V, Vaughn W, Valdes SO, et al. Left ventricular noncompaction cardiomyopathy in children: Characterization of clinical status using tissue Doppler-derived indices of left ventricular diastolic relaxation. Heart 2007; 93: 676-681.

40. Lofiego C, Biagini E, Ferlito M, Pasquale F, Rocchi G, Perugini E, et al. Paradoxical contributions of non-compacted and compacted segments to global left ventricular dysfunction in isolated left ventricular noncompaction. Am J Cardiol 2006; 97: 738-741.
41. Soler R, Rodriguez E, Monserrat L, Alvarez N. MRI of subendocardial perfusion deficits in isolated left ventricular noncompaction. $J$ Comput Assist Tomogr 2002; 26: 373-375.

42. Junga G, Kneifel S, Von Smekal A, Steinert H, Bauersfeld U. Myocardial ischemia in children with isolated ventricular non-compaction. Eur Heart J 1999; 20: 910-916.

43. Jenni R, Wyss CA, Oechslin EN, Kaufmann PA. Isolated ventricular noncompaction is associated with coronary microcirculatory dysfunction. J Am Coll Cardiol 2002; 39: 450-454.

44. Saito K, Ibuki K, Hirono K, Watanabe S, Watanabe K, Uese K, et al. Successful cardiac resynchronization therapy in a 3-year-old girl with isolated left ventricular noncompaction and narrow QRS complex. Circ J 2009 (in press).

45. Oginosawa Y, Nogami A, Soejima K, Aonuma K, Kubota S, Sato T, et al. Effect of cardiac resynchronization therapy in isolated ventricular noncompaction in adults: Follow-up of four cases. $J$ Cardiovasc Electrophysiol 2008; 19: 935-938.

46. Sasse-Klaassen S, Gerull B, Oechslin E, Jenni R, Thierfelder L. Isolated noncompaction of the left ventricular myocardium in the adult is an autosomal dominant disorder in the majority of patients. Am J Med Genet A 2003; 119A: 162-167.

47. Bione S, D'Adamo P, Maestrini E, Gedeon AK, Bolhuis PA, Toniolo D. A novel X-linked gene, G4.5, is responsible for Barth syndrome. Nat Genet 1996; 12: 385-389.

48. Bleyl SB, Mumford BR, Thompson V, Cary JC, Pysher TJ, Chin TK, et al. Neonatal lethal noncompaction of the left ventricle is allelic with Barth syndrome. Am J Hum Genet 1997; 61: 868-872.

49. Bissler JJ, Tsoras M, Goring HH, Hug P, Chuck G, Tombragel E, et al. Infantile dilated X-linked cardiomyopathy, G4.5 mutations, altered lipids, and ultrastructural malformations of mitochondria in heart, liver, and skeletal muscle. Lab Invest 2002; 82: 335-344.

50. Yoshida M, Hama H, Ishikawa-Sakurai M, Imamura M, Mizuno Y, Araishi K, et al. Biochemical evidence for association of dystrobrevin with the sarcoglycan-sarcospan complex as a basis for understanding sarcoglycanopathy. Hum Mol Genet 2000; 9: 1033-1040.

51. Metzinger L, Blake DJ, Squier MV, Anderson LV, Deconinck AE, Nawrotzki R, et al. Dystrobrevin deficiency at the sarcolemma of patients with muscular dystrophy. Hum Mol Genet 1997; 6: 11851191

52. Grady RM, Grange RW, Lau KS, Maimone MM, Nichol MC, Stull JT, et al. Role for alpha-dystrobrevin in the pathogenesis of dystrophin-dependent muscular dystrophies. Nat Cell Biol 1999; 1: 215220.

53. Zhou Q, Chu PH, Huang C, Cheng CF, Martone ME, Knoll GD, et al. Ablation of Cypher, a PDZ-LIM domain Z-line protein, causes a severe form of congenital myopathy. J Cell Biol 2001; 155: 605-612.

54. Shan L, Makita N, Xing Y, Watanabe S, Futatani T, Ye F, et al. SCN5A variants in Japanese patients with left ventricular noncompaction and arrhythmia. Mol Genet Metab 2008; 93: 468-474

55. Wong JA, Bofinger MK. Noncompaction of the ventricular myocardium in Melnick-Needles syndrome. Am J Med Genet 1997; 71: $72-$ 75 .

56. Mandel K, Grunebaum E, Benson L. Noncompaction of the myocardium associated with Roifman syndrome. Cardiol Young 2001; 11: 240-243.

57. Corrado G, Checcarelli N, Santarone M, Stollberger C, Finstere J. Left ventricular hypertrabeculation/noncompaction with PMP22 duplication-based Charcot-Marie-Toth disease type 1A. Cardiology 2006; 105: 142-145.

58. Stollberger C, Finsterer J, Voigtlander T, Slany J. Is left ventricular hypertrabeculation/noncompaction a cardiac manifestation of Fabry's disease? Z Kardiol 2003; 92: 966-969.

59. McMahon CJ, Chang AC, Pignatelli RH, Miller-Hance WC, Eble BK, Towbin JA, et al. Left ventricular noncompaction cardiomyopathy in association with trisomy 13. Pediatr Cardiol 2005; 26: $477-$ 479.

60. Pauli RM, Scheib-Wixted S, Izumo S, Sekhon GHS. Ventricular noncompaction and chromosome 5q deletion. Am J Med Genet 1999; 85: $419-423$

61. Kanemoto N, Horigome H, Nakayama J, Ichida F, Xing Y, Buonadonna AL, et al. Interstitial 1q43-q43 deletion with left ventricular noncompaction myocardium. Eur J Med Genet 2006; 49: $247-253$.

62. Davili Z, Johar S, Hughes C, Kveselis D, Hoo J. Succinate dehydrogenase deficiency associated with dilated cardiomyopathy and ventricular noncompaction. Eur J Pediatr 2007; 166: 867-870. 